\title{
Social Media In Government: From eGovernment To eGovernance
}

Mohammad Dadashzadeh, Oakland University, USA

\begin{abstract}
Over the past five years, Web 2.0 has transformed the Internet by allowing previously passive web surfers to become active content creators who want to share. Companies have been quick to jump on the bandwagon to invest in social media in order to engage their customers, and governments have followed businesses in trying Web 2.0 technologies and are now focusing on investments in social media as a part of their IT strategy. But, should the adoption of social media in government follow the same trial and error approach that business has used? Or, are there inherently different mission-related parameters that dictate different cost benefit analysis for investment in the use of social media in government? In this paper, we consider these questions in light of Accenture's Public Service Value Governance Framework.
\end{abstract}

Keywords: Web 2.0, Social Media, e-Government, e-Governance, Accenture

\section{INTRODUCTION}

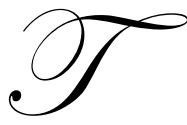

he advent of e-commerce in 1995 gave rise to two megatrends - shattering distance and increasing expectations. No longer were businesses protected by geographical distance from their competitors who could now compete with them directly from their virtual storefronts. At the same time, previously captive customers were now empowered to benchmark a business against the best in industry, creating increased expectations. With the megatrends understood, businesses embarked on adopting e-business practices to manage customer expectations.

Governments were soon to follow the proven e-business practice of providing self-service to customers. Government was made easy by providing citizens 24/7 access to information, forms, and common citizen-togovernment transaction processing, such as renewing automobile registrations or filing taxes. Investments in egovernment were guided by the objectives of improving service delivery and realizing cost efficiencies. Today, egovernment has become de facto synonymous with government, improving public access to information and services through online channels, sharing data within and across organizations, and improving the efficiency of business processes.

Over the past five years, Web 2.0 has transformed the Internet by allowing previously passive web surfers to become active content creators who want to share. Companies have been quick to jump on the bandwagon to invest in social media to engage their customers, to provide them with a soapbox, to participate in their conversations, to get to know them better, and even to leverage their knowledge for product development.

Once again, governments have followed businesses in trying Web 2.0 technologies and having witnessed the success of these technologies in election campaigns, they are now focusing on investments in social media as a part of their IT strategy. But, should the adoption of social media in government follow the same trial and error approach that business has used? Or, are there inherently different mission-related parameters that dictate different cost benefit analysis for investment in the use of social media in government? In this paper, we consider these questions in light of Accenture's Public Service Value Governance Framework (Accenture, 2010). 
Section 2 reviews representative Web 2.0 technologies in government. In section 3, we consider guidelines for strategic use of social media in government. Section 4 examines barriers and potential solutions for adopting Web 2.0 technologies in government. We conclude in section 5 by considering Accenture's framework for moving from e-government to e-governance.

\section{WEB 2.0 AND GOVERNMENT}

The variety of technologies that fall under the umbrella term of Web 2.0 have, to varying degrees, been deployed by local, regional, and national governments both in the US as well as abroad. These technologies are briefly reviewed in this section and representative deployments identified (see also, Campbell and Flagg, 2008; Godwin, 2008).

\subsection{Blogs with Social Collaboration (Comments)}

Blogs such as Kentucky governors' provide the opportunity to put a human face on government taking advantage of the informal tone a blog offers. Blogs can be effectively used to open public conversations, surface issues and solve them.

\subsection{Wikis for Collaborative Authoring and Editing}

Wikis provide an ideal platform for workgroup or public collaboration for project management, knowledge sharing, and public input. The Collaborative Work Environment (COLAB) is hosted by General Services Administration and represents a successful intergovernmental solution.

\subsection{RSS Syndicated Web Feeds}

The simple idea of pushing information to subscribers expands the reach of a government agency to its citizen for automated notifications of frequently updated content of interest. The Environmental Protection Agency (EPA) offers extensive news feeds on various topics and locations.

\subsection{Podcasting}

Podcasting, or multimedia content subscribed to for use on iPod, mp3 players, and computers, provides a governmental agency with more ways to get its message out, and to build trust using a conversational voice. It can be used effectively for updates, live government deliberations, emergencies, and how-to messages. The White House podcasts its press briefings as well as the President's weekly address.

\subsection{Photo Sharing}

Sharing photos (with possibility for comments) helps create awareness and reach new audiences. The Library of Congress' photostream on Flickr is one of many governmental agencies' efforts in taking advantage of external services for photo sharing.

\subsection{Video Sharing}

There are many ways that sharing videos can support an agency's mission ranging from marketing itself to how-to videos and audios in order to improve service. NASA has used YouTube effectively to make its case for why should the US explore space. Videos can support public outreach, education, and training. And, they are preferred as a communication channel for a segment of online citizens.

\subsection{Social Bookmarking, News Sharing, and Tagging}

Social bookmarking and tagging are ways of sharing content with others. They can also be effectively used to promote articles and increase the popularity and use of government sites. 


\subsection{Social Networking}

Social networking is about people with similar interests building a virtual community. Its lynchpin is building trust that leads one to share what is valuable (one's knowledge for example). That, in turn, engages others to move from taking value to adding value by participating, thereby completing the cycle and creating true collaboration. Social networking can be used by agencies in a variety of ways ranging from creating cross government coordination and knowledge management to recruitment activities and supporting event announcements to the public.

An agency can participate in externally run social networking sites (such as Facebook) or undertake the building of its own site. In May 2008, a US government employee took the initiative to launch GovLoop, a social networking site that now connects about 25,000 federal, state and local government employees, academics and contractors

\section{$2.9 \quad$ Virtual Worlds}

Virtual worlds are simulations of environments and people. They provide for public outreach to a niche audience. They offer the ability to bring people together worldwide for meetings and lectures to advance an agency's education and training missions. The Center for Disease Control and Prevention (CDC) has been a leader in the use of social media including Second Life.

\subsection{Mashups}

Mashups represent a very promising Web 2.0 technology for combining content from multiple sources to create an integrated web-based application. Because of the amount of public data available to government, government agencies are in a unique position to take advantage of mashups for providing data to others who can create applications with increased value for the public. The first edition of Apps for Democracy initiative by the District of Columbia yielded 47 web, iPhone, and Facebook applications in 30 days - a $\$ 2,300,000$ value to the city at a cost of $\$ 50,000$.

\subsection{Widgets}

Widgets are small applications and code in web pages, or for desktop use, that bring (syndicated) content to the user. They can promote awareness, use, and usefulness of government sites, information, and service. Federal Bureau of Investigation (FBI) has several widgets, including the Most Wanted List, available for download and use.

\subsection{Microblogging}

A form of blogging which allows brief (instant message) size text updates, as popularized by Twitter, can be used to broadcast messages in emergencies or for real time reporting. Washington State Department of Transportation has been an early adopter that has noticed the positive side effect of having fewer loads on its web server during emergencies since it started using Twitter.

\section{STRATEGIC USE OF SOCIAL MEDIA IN GOVERNMENT}

The investment decision for social media technologies and applications in government, as in business, must be a part of the organization's enterprise architecture planning effort. Figure 1, an adaptation of the Input/Output Model of IT Planning (Dadashzadeh, 2009), identifies the necessary steps for strategic use of social media in government. 


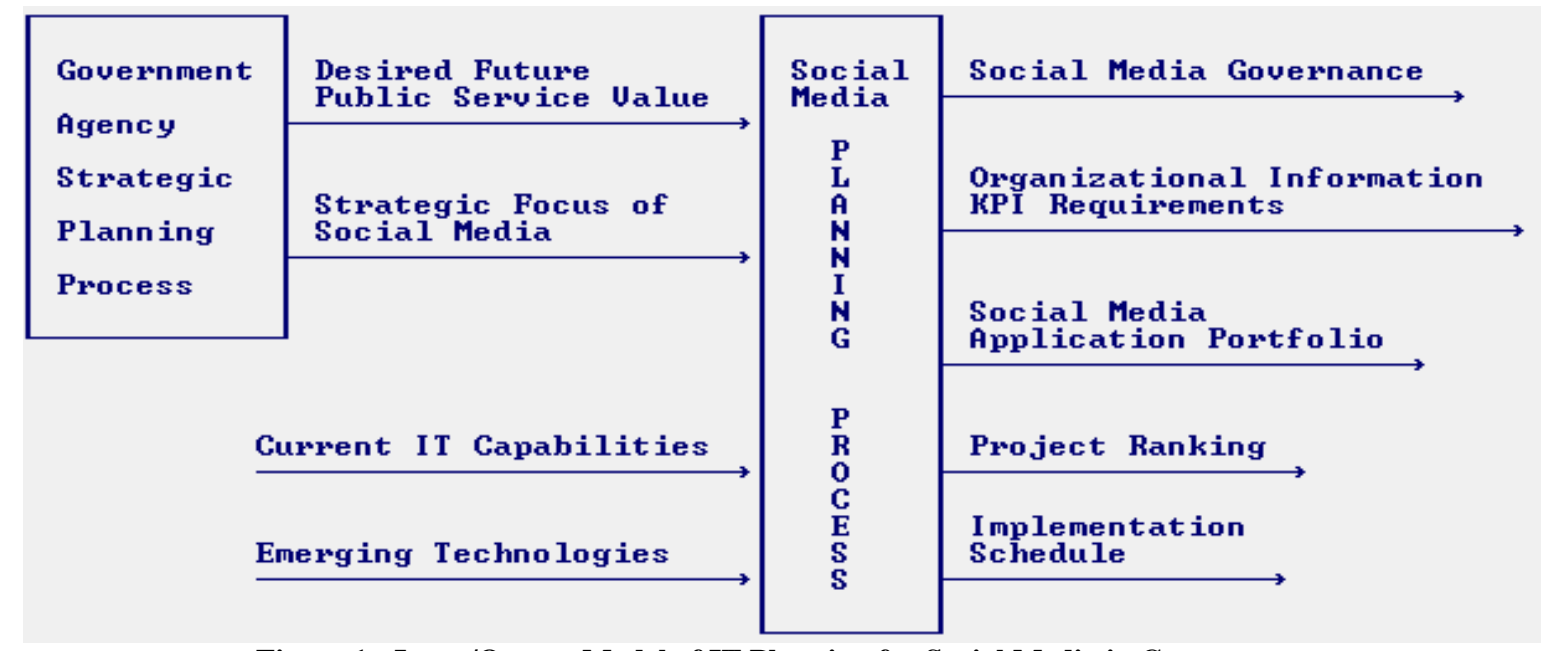

Figure 1: Input/Output Model of IT Planning for Social Media in Government

To begin, a government agency's strategic planning process must define the desired future public service value to be created by the agency and the strategic focus of social media in realizing it. According to Accenture's Public Service Value Governance Framework (Accenture, 2010), the desired public service value to be created and the role of social media in realizing it must be guided by four principles:

1. Outcomes-Based Focus - Generating tangible improvements in the social and economic conditions of citizens

2. Balanced to Ensure Fairness - Serving the common good by providing access for all citizens

3. Engagement to Co-Produce Public Value - Engage, educate, but also help citizens improve their own quality of life by tapping into their experience

4. Improving Government Accountability - Increasing transparency in reporting cost-effectiveness of initiatives and providing citizens the opportunity to "talk back" when governments fail to deliver expected public value

The strategic steps also include an inventory of current IT capabilities and a forecast of emerging technologies and trends. Social media can enable internal communication and collaboration, exchange information with the public, and keep pace with fast moving events in real time. Twitter alone grew 1,382\% year-over-year in February 2009, registering a total of just more than 7 million unique visitors in the US for the month (Ostrow, 2009). It is not unreasonable to expect that social media will become even more popular, more mobile, and more exclusive (Armano, 2009). As pointed out by Armano (2009), with approximately 70 percent of organizations banning social networks, accessing social networks through mobile devices will increase. And, with websites providing the sharing functionality which allows a user to easily broadcast an article across networks such as Facebook and Twitter, it will become more mainstream for people to share with networks what they used to share with e-mail. Both of these trends have strong ramifications on IT planning for an agency's social media application portfolio.

Given the desired future public service value to be created by the agency and the strategic focus of social media, and an inventory of current IT capabilities and a forecast of emerging technologies and trends, the agency's social media planning process must produce five outputs. First and foremost, it is necessary to formalize how the agency views social media and the employees' participation in it. There are obstacles stemming from the clash of the laissez faire nature of social media with the beuracratic nature of government that need to be addressed. Moreover, decision rights and responsibilities of organizational units and specific rules of engagement across multiple social media networks must be put in place for the benefit of the agency's social media governance.

The remaining outputs are a mapping of the agency's defined desired future public service value to be created onto social media tools, technologies, and application portfolio to be planned and scheduled for 
implementation. Each social media initiative should serve a well-defined, mission-oriented purpose, and have the potential to improve the agency's communications efforts. It is imperative to define the key performance indicators (KPI) that define what success looks like and how it will be measured. After all, although social media can uncover cost savings, its strength lies in increasing citizen engagement to harness the collective ingenuity of the public to coproduce tangible improvements for the common good.

Like any other IT investment, social media investments need to be planned and the required concomitant organizational change to culture, people, structure, and processes be managed for effective results. Although, it is reasonable to start small to see which initiatives work and which do not, the maneuverability of government in adopting social media by the trial and error approach is markedly lower than business. Therefore, a strategic planning approach as presented here becomes necessary for effectively leveraging social technology in government.

\section{BARRIERS AND POTENTIAL SOLUTIONS}

The adoption of social media technologies by government agencies surfaces issues that emanate from the clash of the free-form nature of social media with the beuracratic nature of most government rules and standard operating procedures. In a 2008 study of issues relevant to the US, Godwin et al. (2008) identify ten barriers and recommend potential solutions. Table 1 categorizes the ten barriers as strategy formulation issues, policies for using non-government sites, and issues in using government owned social networking sites.

Table 1: Issues in Adoption of Social Media Technologies in Government

\begin{tabular}{|c|c|}
\hline Issue Category & Issue \\
\hline Strategy Formulation & $\begin{array}{l}\text { 1. Cultural unpreparedness and lack of strategy for using social media } \\
\text { technologies }\end{array}$ \\
\hline Non-Government Site Usage & $\begin{array}{l}\text { 2. Blocking employee access to social media sites } \\
\text { 3. Agreeing to terms of service required by social media sites } \\
\text { 4. Advertising placed on pages by social media sites } \\
\text { 5. Government procurement rules for "free" service offered } \\
\text { 6. Privacy standards and enforcements of social media sites }\end{array}$ \\
\hline Government Site Usage & $\begin{array}{l}\text { 7. Prohibition of persistent cookies as would be required for site } \\
\text { personalization } \\
\text { 8. Rules requiring an OMB control number to survey and request information } \\
\text { from the public } \\
\text { 9. Providing access for people with disabilities including transcripts/captions } \\
\text { on audio/video content } \\
\text { 10. Administrative requirements during rulemaking on how to accept comments } \\
\text { from public on new regulations }\end{array}$ \\
\hline
\end{tabular}

\section{CONCLUSIONS}

For local, regional, and national governments, managing the increased expectations of citizens will remain a strategic necessity. Inasmuch as the Internet, or the global village created by it, takes the lion's share for giving rise to this megatrend, it is also the tidal force behind the cultural shift represented by social media that feeds the increasing citizens' expectations. And, governments must, once again, address the Internet.

The government's initial response to adopting Internet technologies paved the way for moving government to e-government by justifying return on investment (ROI) based on cost efficiencies and improving service delivery. However, social media technologies do not offer clear-cut ROI justifications based on cost efficiencies or service delivery. And, while businesses can choose the customers they target, governments are there to serve the common good of all citizens. Therefore, adoption of social media in government must be more carefully planned out.

As presented in this paper, Accenture's Public Service Value Framework, along with the Input/Output Model for IT Planning, offer a needed guideline for evaluating the social media initiatives that allow a strategic transition from e-government to web-based participatory government or e-governance. A transition plan based on 
four principles of tangible outcomes, access for all citizens through targeted information and tailored services, engaging citizens and their experience for co-producing public value, and increasing transparency and accountability of government.

Social media tools can exchange information with the public and harness the collective ingenuity of the public to support the agency's mission. Often social media can uncover cost savings, but its strength really lies in increasing audience engagement - which helps a government agency accomplish its mission. After all, as pointed out by Goethe, the best government is that which teaches us to govern ourselves.

\section{AUTHOR INFORMATION}

Mohammad Dadashzadeh is Professor of MIS at Oakland University. He has been affiliated with University of Detroit (1984-1989), Wichita State University (1989-2003) where he served as the W. Frank Barton Endowed Chair in MIS, and the Applied Technology in Business (ATiB) Program (2003-2009) at Oakland University where he directed more than two million dollars of funded projects at sponsoring organizations. Dr. Dadashzadeh has authored 4 books and more than 50 articles on information systems and has served as the editor-in-chief of Journal of Database Management. He has extensive consulting experience and more than 6,000 people have attended his professional training seminars worldwide. Dr. Dadashzadeh is a co-author of Iranian Standard Code for Information Interchange (ISCII) and a co-founder of Sinasoft.

\section{REFERENCES}

1. Accenture, “Accenture Public Service Value Governance Framework,” accenture.com, June 28, 2010, http://www.accenture.com/Global/Research_and_Insights/Institute_For_Public_Service_Value/AccentureF ramework.htm.

2. Armano, D., "Six Social Media Trends for 2010," November 2, 2009, Harvard Business Review, June 28, 2010, http://blogs.hbr.org/cs/2009/11/six_social_media trends.html.

3. Campbell, S., and Flagg, R., "Examples of Agencies Using Online Content and Technology to Achieve Mission and Goals," November 26, 2008, USA.gov, June 28, 2010. http://www.usa.gov/webcontent/documents/ExamplesofUsingTechnologyandContenttoAchieve\%20Agenc y.pdf.

4. $\quad$ Dadashzadeh, M., “A New Methodology for Developing the MIS Master Plan," Review of Business Information Systems, 13(1), pp. 15-23, 2009.

5. Godwin, B., "Matrix of Web 2.0 Technology and Government," June 18, 2008, USA.gov, June 28, 2010, http://www.usa.gov/webcontent/documents/Web_Technology_Matrix.pdf.

6. Godwin, B., et al., "Social Media and the Federal Government: Perceived and Real Barriers and Potential Solutions," December 23, 2008, USA.gov, June 28, 2010, http://www.usa.gov/webcontent/documents/SocialMediaFed\%20Govt_BarriersPotentialSolutions.pdf.

7. Ostrow, A., "Twitter Now Growing at a Staggering 1,382 Percent," March 16, 2009, mashable.com, June 28, 2010, http://mashable.com/2009/03/16/twitter-growth-rate-versus-facebook. 